Supporting Information

for

Composite Gel Polymer Electrolyte Based on Poly(vinylidene fluoridehexafluoropropylene) (PVDF-HFP) with Modified Aluminum-Doped

Lithium Lanthanum Titanate (A-LLTO) for High-Performance

\title{
Lithium Rechargeable Batteries
}

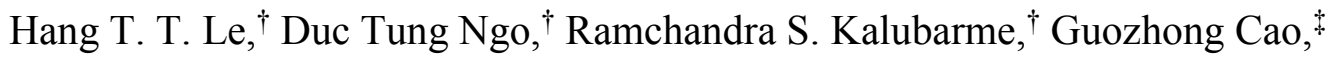
Choong-Nyeon Park, ${ }^{\dagger}$ and Chan-Jin Park ${ }^{\dagger}, *$

${ }^{\dagger}$ Department of Materials Science and Engineering, Chonnam National University, 77 Yongbongro, Bukgu, Gwangju 500-757, South Korea

* Department Department of Materials Science and Engineering, University of Washington, Seattle, Washington 98195-2120, United States

* Corresponding author.

Tel.: +82-62-530-1704;

Fax: +82-62-530-1699

E-mail address: parkcj@jnu.ac.kr (‥J. Park) 
Table S1. Influence of mass ratio of PVDF-HFP to A-LLTO/m-SiO 2 on the properties of gel polymer electrolytes.

\begin{tabular}{cccccc}
\hline $\begin{array}{c}\text { Mass ratio of } \\
\text { PVDF-HFP to } \\
\text { A-LLTO/m-SiO } 2\end{array}$ & $\begin{array}{c}\text { Content of } \\
\text { A-LLTO/m-SiO } 2\end{array}$ & $\begin{array}{c}\text { Thickness } \\
(\mu \mathrm{m})\end{array}$ & $\begin{array}{c}\text { Bulk resistance } \\
(\mathrm{wt} \%\end{array}$ & $\begin{array}{c}\text { Conductivity } \\
\left(\mathrm{S} \mathrm{cm}^{-1}\right)\end{array}$ & $\begin{array}{c}\text { Hardness }\left(\mathrm{H}_{\mathrm{D}}\right), \\
\text { before activation }\end{array}$ \\
\hline $10: 0$ & 0 & 85 & 2.73 & $1.56 \times 10^{-3}$ & 22.6 \\
$8: 2$ & 20 & 102 & 3.57 & $1.43 \times 10^{-3}$ & 45.7 \\
$6: 4$ & 40 & 96 & 3.53 & $1.36 \times 10^{-3}$ & 56.8 \\
$4: 6$ & 60 & 109 & 4.22 & $1.29 \times 10^{-3}$ & 67.8 \\
$3: 7$ & 70 & 104 & 4.13 & $1.26 \times 10^{-3}$ & 74.5 \\
$2: 8$ & 80 & 95 & 3.89 & $1.22 \times 10^{-3}$ & 78.9 \\
$1: 9$ & 90 & 92 & 6.67 & $0.69 \times 10^{-3}$ & 80.1 \\
\hline
\end{tabular}




\section{$\mathrm{Li}_{-\mathrm{LiCoO}}$ cell}

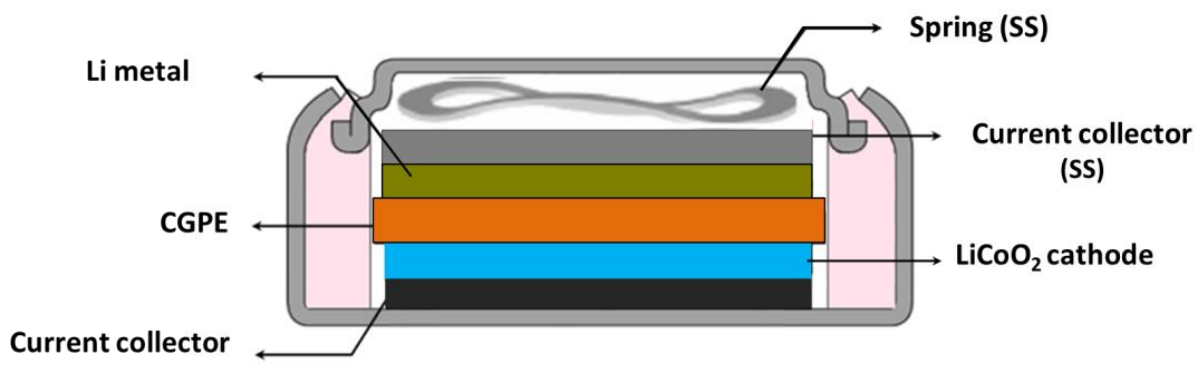

(Al)

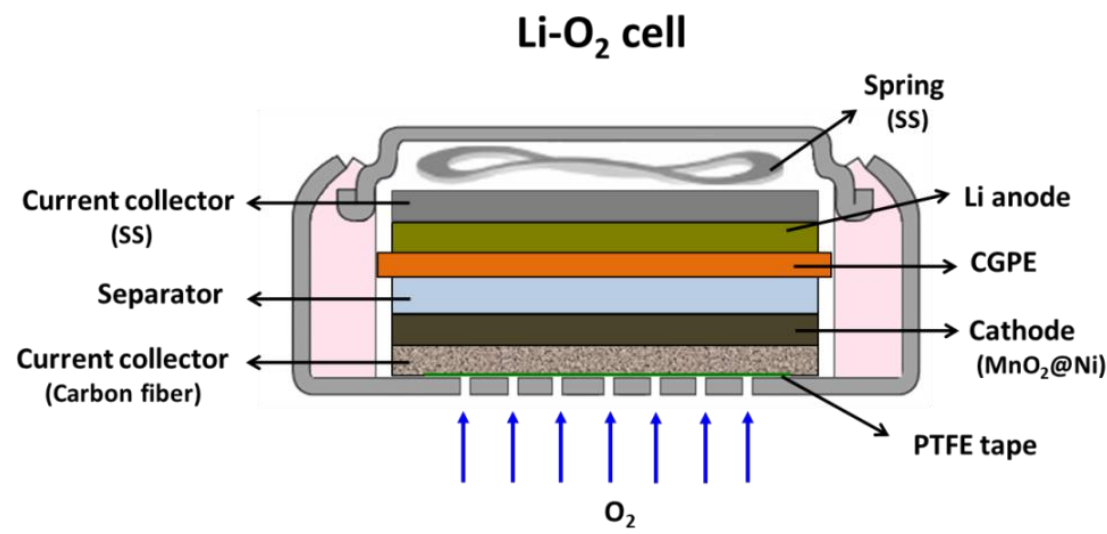

Figure S1. Schematic for the configuration of $\mathrm{Li}-\mathrm{LiCoO}_{2}$ and $\mathrm{Li}-\mathrm{O}_{2}$ cells. 


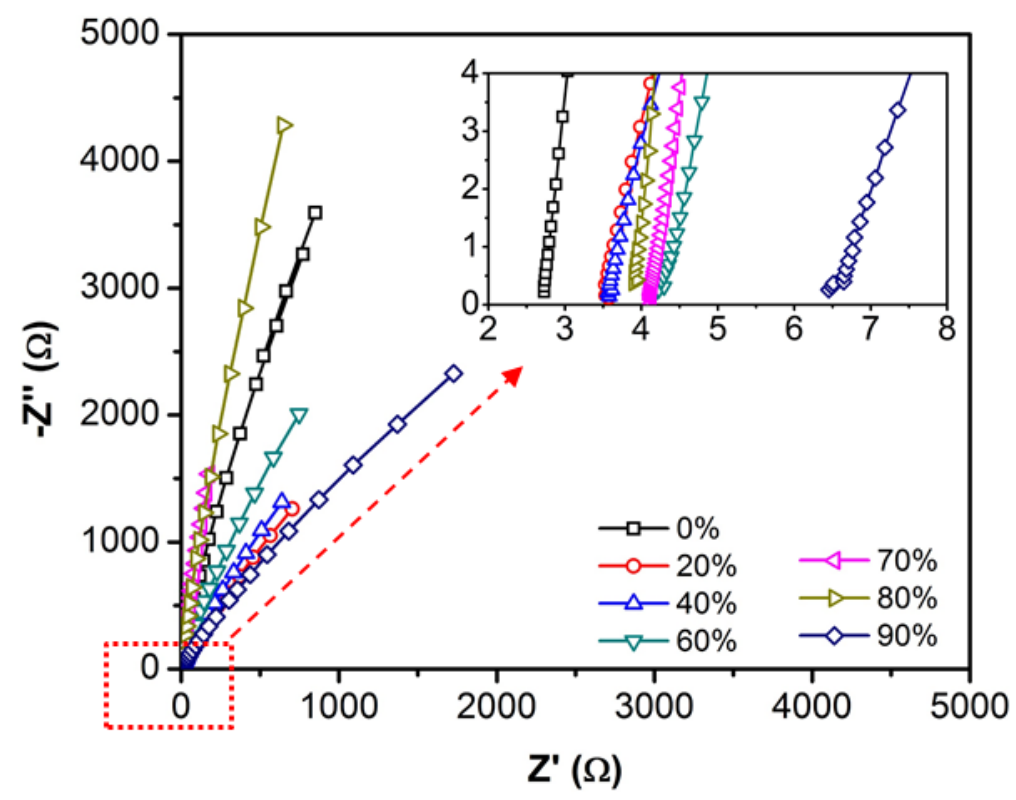

Figure S2. Electrochemical impedance spectra for the gel polymer electrolytes (GPE) based on PVDF-HFP and the composite gel polymer electrolyte (CGPE) based on the PVDF-HFP with various content of $\mathrm{A}-\mathrm{LLTO} / \mathrm{m}-\mathrm{SiO}_{2}$ from 20 to $90 \mathrm{wt} . \%$.

Figure S2 shows the Nyquist plots for pure gel polymer electrolyte (PVDF-HFP) and composite gel polymer electrolyte (PVDF-HFP $\left.+\mathrm{A}-\mathrm{LLTO} / \mathrm{m}-\mathrm{SiO}_{2}\right)$ obtained after activation in a solution of $1 \mathrm{M} \mathrm{LiPF}_{6}$ in EC/EMC (50:50 in vol\%). From the bulk resistance, $\mathrm{R}_{\mathrm{b}}$ values, measured from impedance spectra and the dimensions of the electrolyte membrane, the ionic conductivities were calculated as shown in Table S1. 


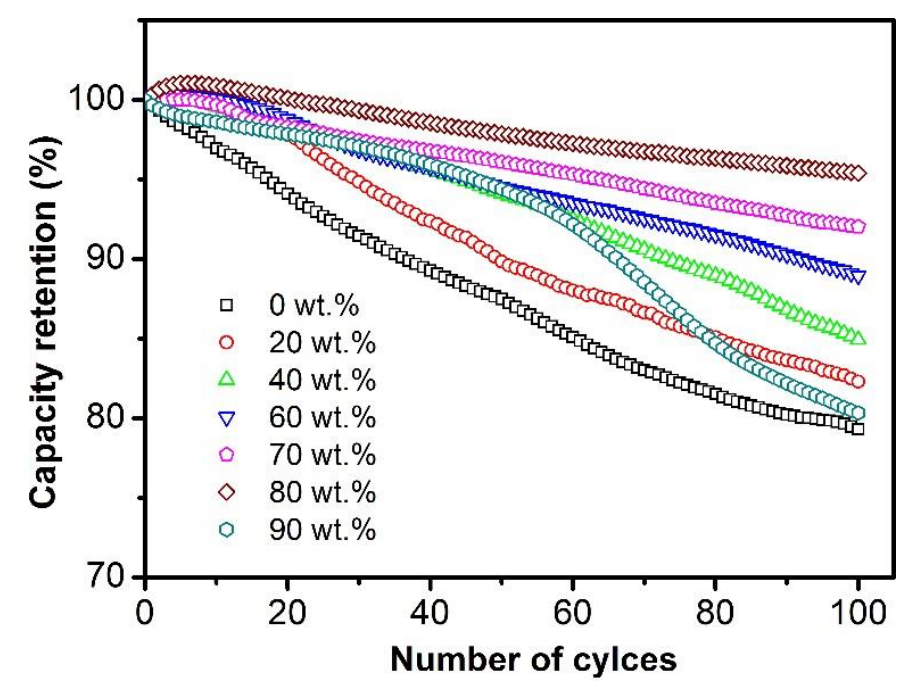

Figure S3. Cyclability of $\mathrm{Li}-\mathrm{LiCoO}_{2}$ cells using a pure gel polymer electrolyte (0 wt.\%) and a composite gel polymer electrolyte with various content of $\mathrm{A}-\mathrm{LLTO} / \mathrm{m}-\mathrm{SiO}_{2}$ from 20 to 90 wt.\%, tested at 1C-rate of charge and discharge for 100 cycles.
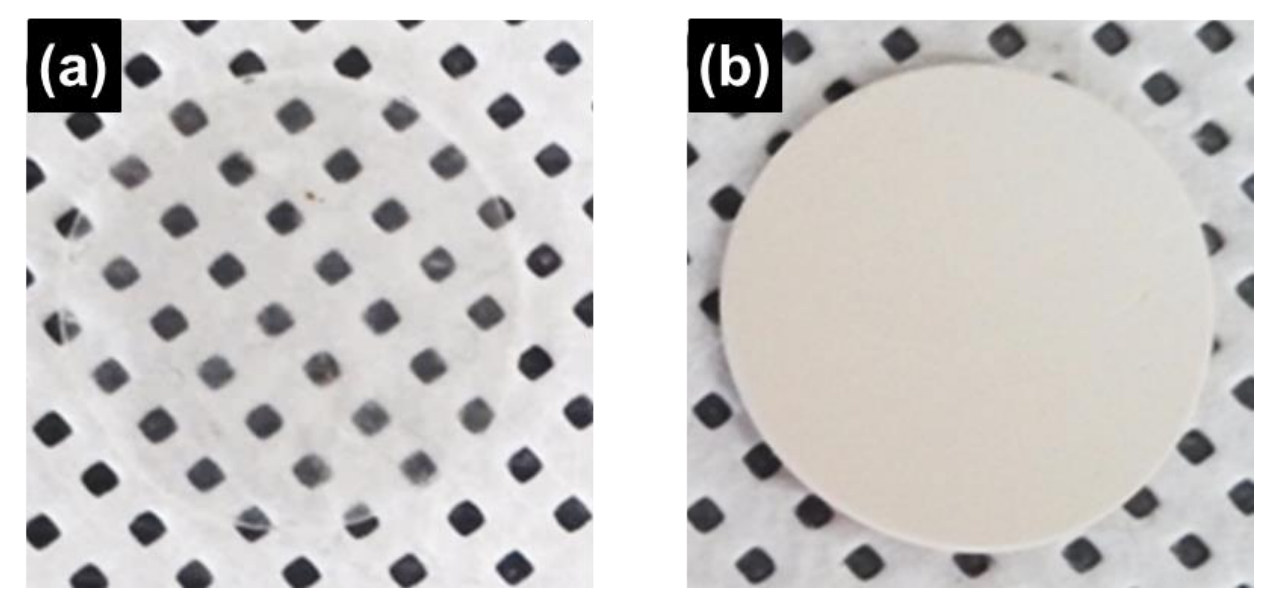

Figure S4. Photos of (a) pure GPE and (b) CGPE after activation in the liquid electrolyte of $1 \mathrm{M}$ $\mathrm{LiPF}_{6}$ in $\mathrm{EC} / \mathrm{EMC}(50 / 50$ in vol\%). 


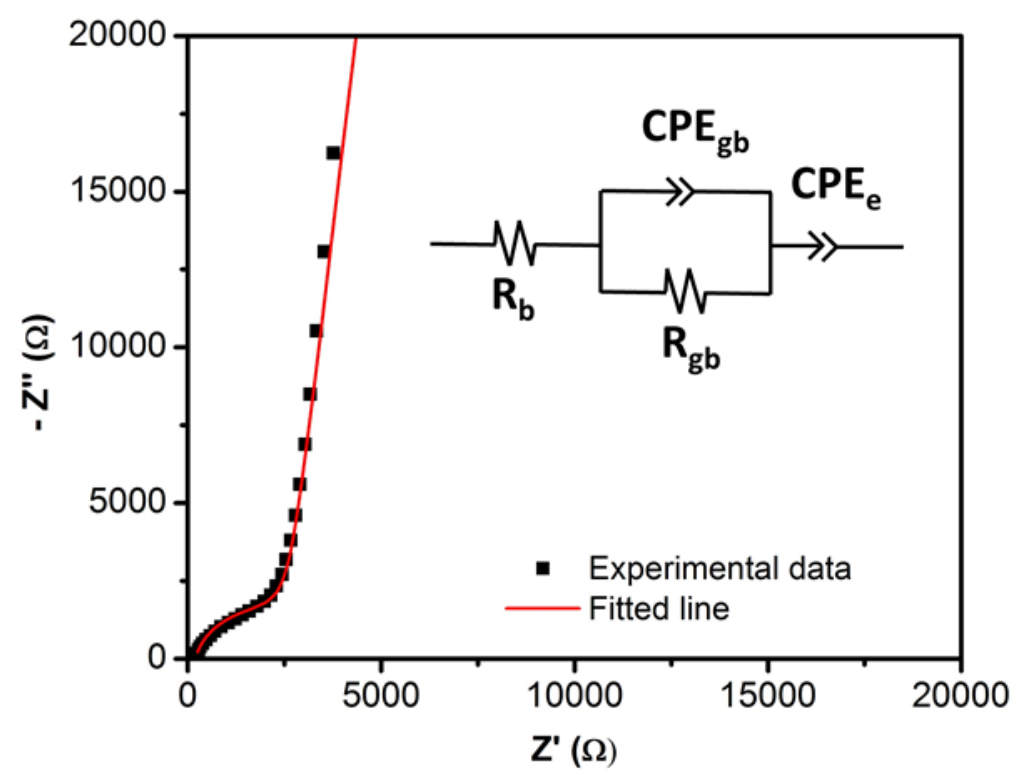

Figure S5. Impedance spectra for the A-LLTO sample (ם) measured at $25^{\circ} \mathrm{C}$. The fitted line (-) simulated based on the equivalent circuit as shown in the inset.

In order to evaluate the influence of $\mathrm{m}-\mathrm{SiO}_{2}$ on the conductivity of A-LLTO/m-SiO $\mathrm{LLTO} / \mathrm{m}-\mathrm{SiO}_{2}$ powder was pelletized, embedded in the powder of the same composition, and sintered at $1350{ }^{\circ} \mathrm{C}$ for $6 \mathrm{~h}$. The surface of pellet was polished carefully using sand papers. The pellet sample with diameter of $6 \mathrm{~mm}$ and thickness of $0.8 \mathrm{~mm}$ was coated with a thin film of platinum on both its surfaces, and silver glue was applied to the surface, before annealing at $500{ }^{\circ} \mathrm{C}$ for $1 \mathrm{~h}$. The Li-ion conductivity of the A-LLTO/m-SiO ${ }_{2}$ composite ceramics was measured by electrochemical impedance using ZIVE SP2 impedance analyzer.

Figure $\mathbf{S 5}$ illustrates the impedance plot of the A-LLTO/m-SiO ${ }_{2}$ measured at $25{ }^{\circ} \mathrm{C}$ and the corresponding equivalent circuit. As seen, the impedance plot includes one arc in the high frequency range (corresponding to the ionic conductivity of the sample) and a spike in low frequency range (corresponding to the blocking effect of the Pt electrode). Therefore, an equivalent circuit as shown in the inset of Figure $\mathbf{S 5}$ was used. Herein, grain component is described by the resistance, $R_{b}$, and grain boundary component is described by the resistance, $R_{\mathrm{gb}}$ in parallel with the constant phase element, $\mathrm{CPE}_{\mathrm{gb}}$. The electrode polarization is indicated by a constant phase element, $\mathrm{CPE}_{\mathrm{e}}$. Excellent coincidence between fitting line and the plot of experimental data indicates that the 
equivalent circuit is appropriate for simulation. After fitting and calculation based on these resistance values, the sample thickness, and electrode area, the bulk and total ionic conductivities of the $\mathrm{A}-\mathrm{LLTO} / \mathrm{m}-\mathrm{SiO}_{2}$ are $\sigma_{\mathrm{b}}=1.29 \times 10^{-3} \mathrm{~S} \mathrm{~cm}^{-1}$ and $\sigma_{\mathrm{gb}}=1.14 \times 10^{-4} \mathrm{~S} \mathrm{~cm}^{-1}$, respectively. Accordingly, the total ionic conductivity was calculated to be $\sigma_{\mathrm{t}}=1.05 \times 10^{-4} \mathrm{~S} \mathrm{~cm}^{-1}$. General, these values is relatively smaller than that of A-LLTO $\left(\sigma_{\mathrm{b}}=2.99 \times 10^{-3} \mathrm{~S} \mathrm{~cm}^{-1}, \sigma_{\mathrm{gb}}=3.55 \times 10^{-4} \mathrm{~S}\right.$ $\mathrm{cm}^{-1}$, and $\sigma_{\mathrm{t}}=3.17 \times 10^{-4} \mathrm{~S} \mathrm{~cm}^{-1}$ ) without $\mathrm{m}-\mathrm{SiO}_{2}{ }^{1}{ }^{1}$ This is attributed to blocking effect of $\mathrm{m}-\mathrm{SiO}_{2}$, which is in high agreement with the previous reports. ${ }^{2-3}$ 

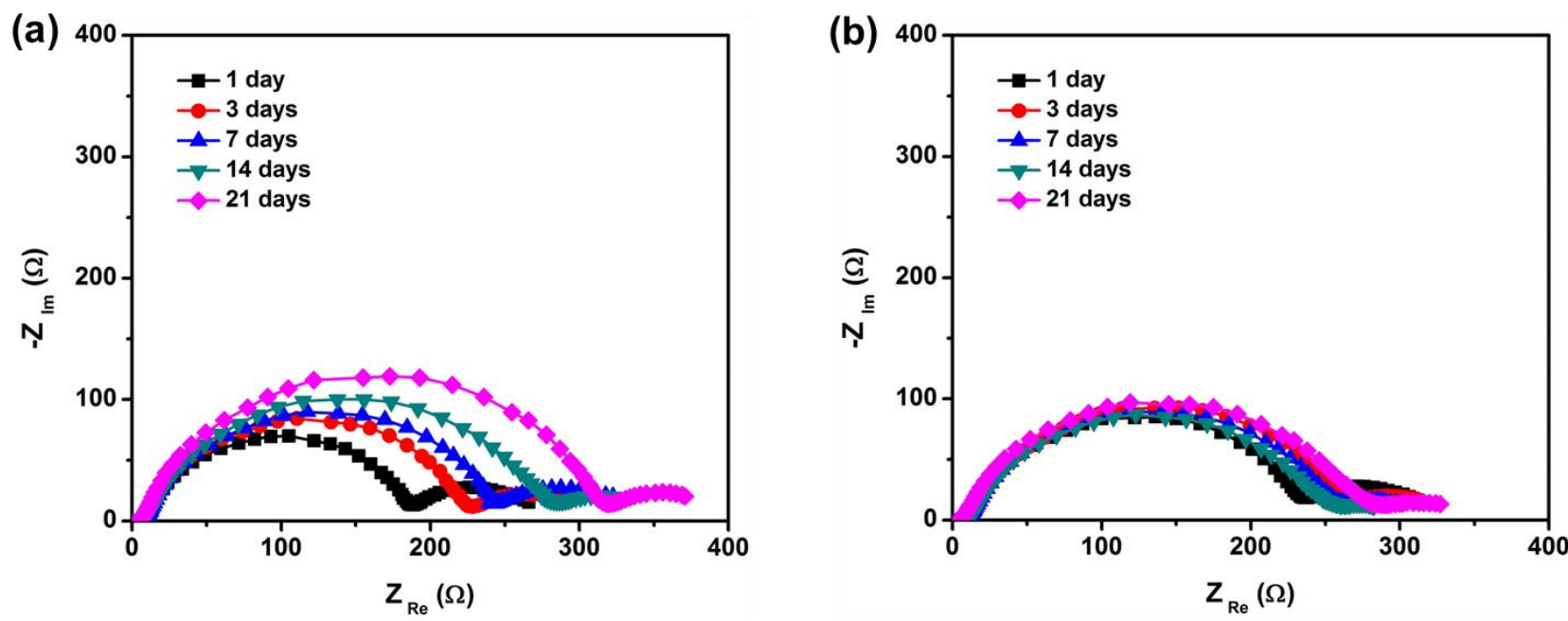

Figure S6. Nyquist impedance plots for the Li/electrolyte/Li symmetric cells employing (a) pure GPE and (b) CGPE.

The typical Nyquist impedance spectra for a symmetric cell of $\mathrm{Li} / \mathrm{gel}$ electrolyte/Li recorded at room temperature with various periods of storage time are presented in Figure S6. A larger depressed semicircle observed in the high frequency range appears to be composed of convoluted two arcs: the first one observed at the higher frequencies represents the parallel combination of the resistance and capacitance of the passive film formed on the Li electrode surface, and the second one at the medium frequencies is attributed to the combination of the charge transfer resistance and double layer capacitance. Another smaller semicircle observed in the low frequency range corresponds to the diffusion resistance. In addition, it is clearly seen that the intersection of the plots with the horizontal axis at the high frequency range, corresponding to bulk resistance, was not changed during the storage time for either sample. However, the magnitude of the depressed semicircle at the high and medium frequencies for the pure GPE increased continuously with storage time. This confirms the continuous interfacial reaction on Li electrodes during storage. In contrast, under the same condition the CGPE formed a stable passive film resulting in little difference among the Nyquist plots obtained for the cells after 21 days of storage. We attribute such an enhanced effect of the CGPE to the presence of inorganic A-LLTO/m-SiO 2 particles. 


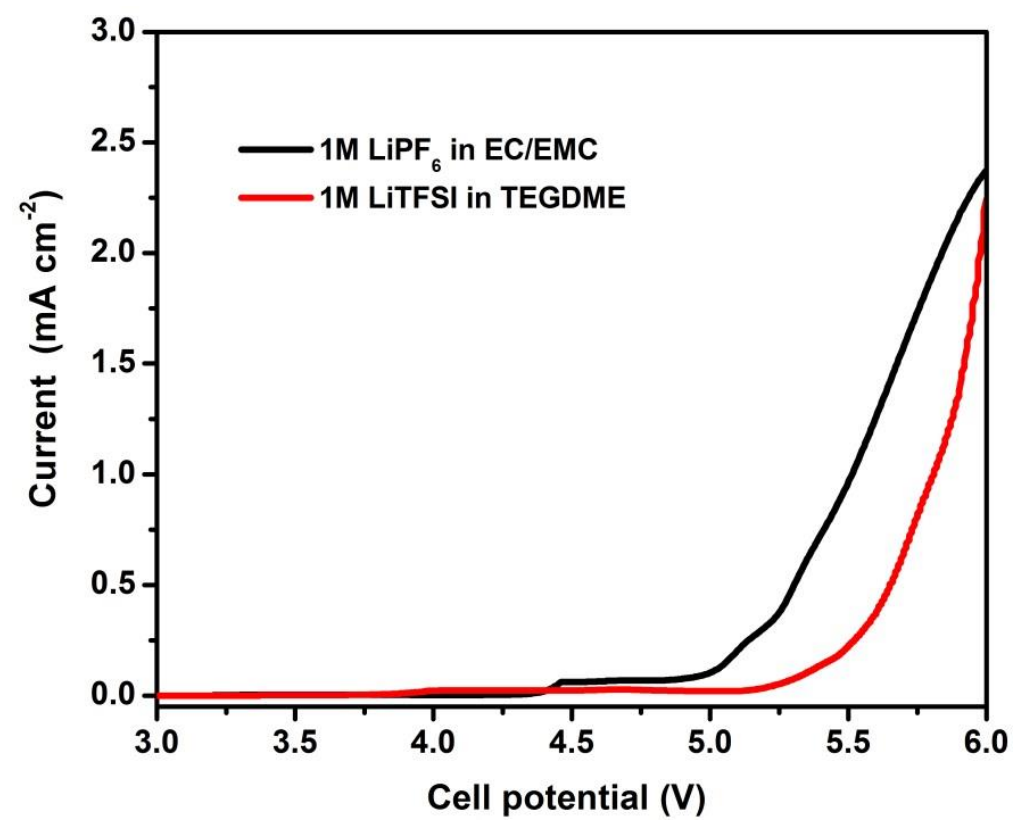

Figure S7. Linear voltammogram for the cell composed of SS/CGPE/Li (SS: stainless steel), where the CGPEs were activated in different liquid electrolytes, measured at the scan rate of $1 \mathrm{mV} \mathrm{s}^{-1}$.

According to Appetecchi's method, ${ }^{4}$ the electrochemical stability window of the composite gel polymer electrolytes (GCPEs) was determined by linear sweep voltammetry using an inert stainless steel (SS) electrode. The liquid electrolytes used to activate the CGPEs were solutions of $1 \mathrm{M} \mathrm{LiPF}_{6}$ in EC/EMC and $1 \mathrm{M}$ LiTFSI in TEGDME. The upper potential limit in the electrolyte stability range was determined as the intersection point between the extension of the linear current region at high potentials and the potential axis. As shown in Figure S7, for all investigated CGPEs, current responses were negligible below $5 \mathrm{~V}$ vs. $\mathrm{Li} / \mathrm{Li}^{+}$. This implies that there is no decomposition of any component in this potential range and the CGPEs have a suitable electrochemical stability up to $5 \mathrm{~V}$ vs. $\mathrm{Li} / \mathrm{Li}^{+}$, which enables the use of the CGPEs for $\mathrm{Li}$-ion or $\mathrm{Li}-\mathrm{O}_{2}$ batteries. 

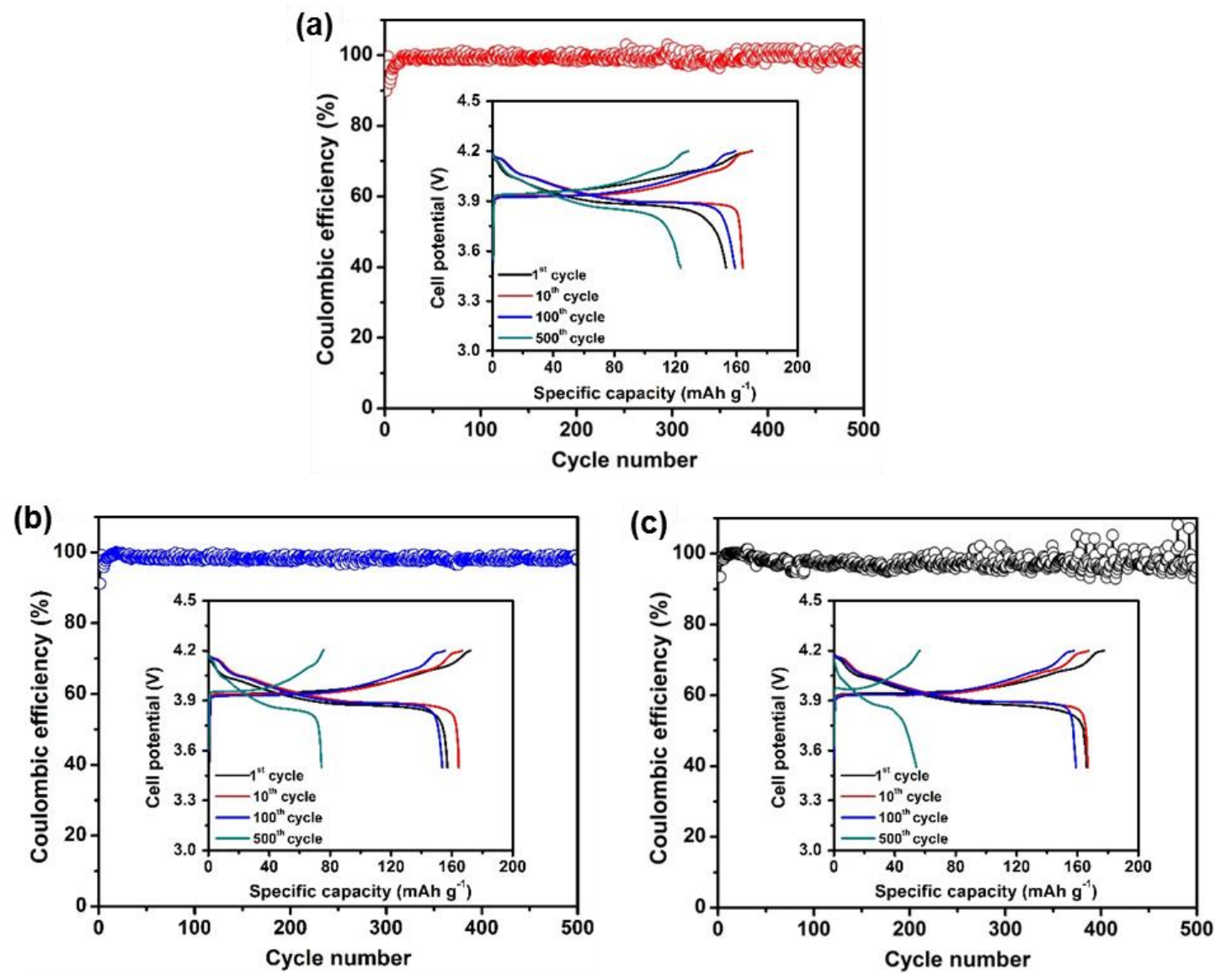

Figure S8. Coulombic efficiency and cell potential profiles (inset) for the $\mathrm{Li}-\mathrm{LiCoO}_{2}$ cells employing (a) the CGPE, (b) the pure GPE and (c) the glass fiber separator under the chargedischarge rate of $0.5 \mathrm{C}$ for 500 cycles; 

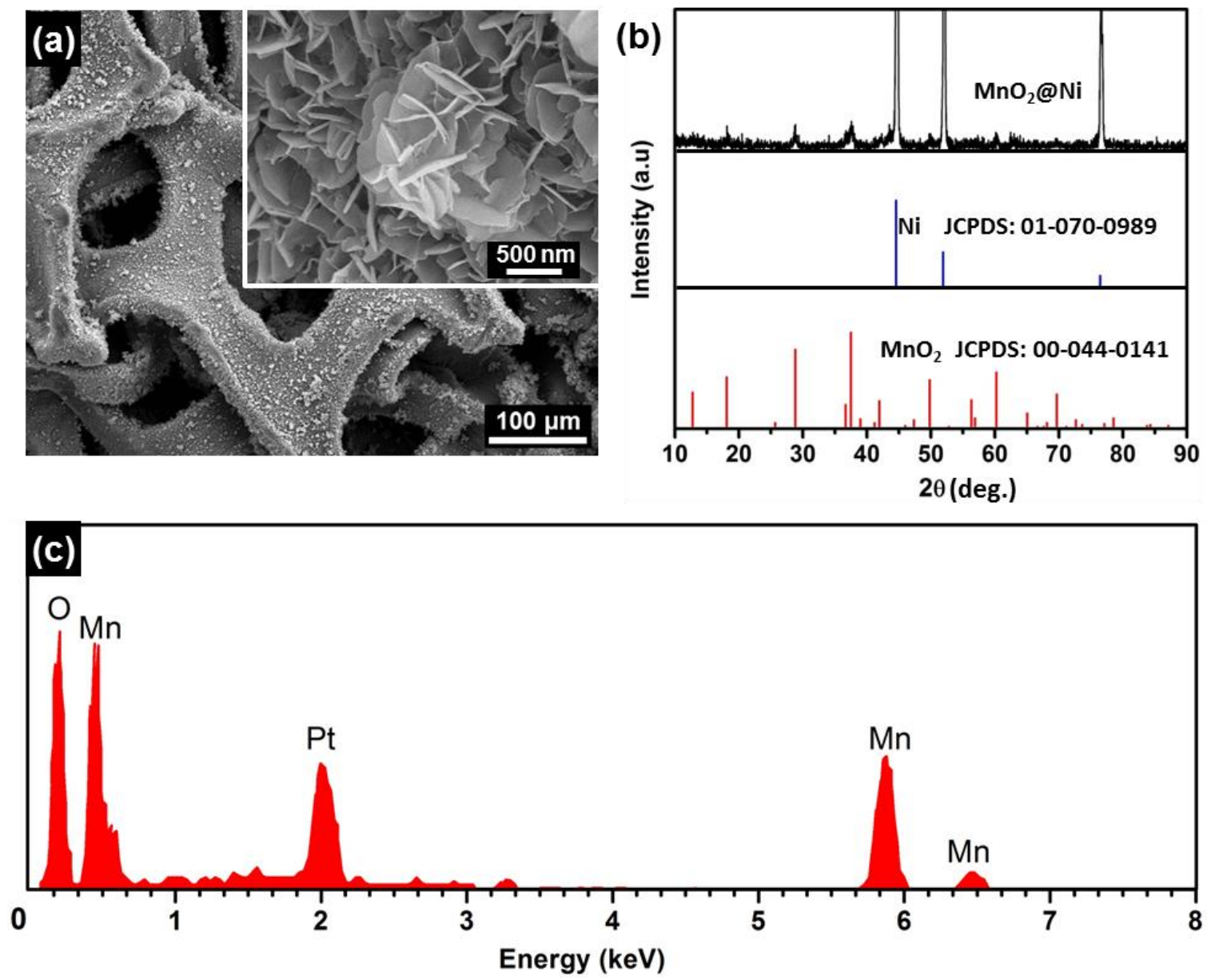

Figure S9. (a) SEM image of carbon-free $\mathrm{MnO}_{2} @ \mathrm{Ni}$ oxygen electrode for Li-O $\mathrm{O}_{2}$ cell; (b) XRD pattern of a $\mathrm{MnO}_{2} @ \mathrm{Ni}$ oxygen electrode compared with standard patterns of $\mathrm{Ni}$ and $\mathrm{MnO}_{2}$ references; (c) EDS spectra for the obtained $\mathrm{MnO}_{2}$ catalysts (Pt signal was from the Pt coating for SEM observation).

The synthesized catalysts for the $\mathrm{Li}-\mathrm{O}_{2}$ cell exhibited tetragonal crystalline nanosheet arrays covering the entire surface of the $\mathrm{Ni}$ foam skeleton with the approximate composition of $\mathrm{Mn}: \mathrm{O}=$ 1:2. Therefore, the material employed as an oxygen electrode for $\mathrm{Li}^{-} \mathrm{O}_{2}$ cell in this work was confirmed to be carbon- and binder-free $\mathrm{MnO}_{2}$. 


\section{References}

(1) Le, H. T. T.; Kalubarme, R. S.; Ngo, D. T.; Jang, S.-Y.; Jung, K.-N.; Shin, K.-H.; Park, C.-J., Citrate Gel Synthesis of Aluminum-Doped Lithium Lanthanum Titanate Solid Electrolyte for Application in Organic-Type Lithium-Oxygen Batteries. J. Power Sources 2015, 274, 1188-1199.

(2) Mei, A.; Wang, X.-L.; Feng, Y.-C.; Zhao, S.-J.; Li, G.-J.; Geng, H.-X.; Lin, Y.-H.; Nan, C.-W., Enhanced Ionic Transport in Lithium Lanthanum Titanium Oxide Solid State Electrolyte by Introducing Silica. Solid State Ionics 2008, 179 (39), 2255-2259.

(3) Deng, Y.; Shang, S.-J.; Mei, A.; Lin, Y.-H.; Liu, L.-Y.; Nan, C.-W., The Preparation and Conductivity Properties of $\mathrm{Li}_{0.5} \mathrm{La}_{0.5} \mathrm{TiO}_{3} /$ Inactive Second Phase Composites. J. Alloys Compd. 2009, 472 (1-2), 456-460.

(4) Appetecchi, G. B.; Croce, F.; Scrosati, B., High-Performance Electrolyte Membranes for Plastic Lithium Batteries. J. Power Sources 1997, 66 (1-2), 77-82. 